\title{
РАЗРАБОТКА КОНЦЕПТУАЛЬНОГО ПОДХОДА К СОЗДАНИЮ ПРОИЗВЕДЕНИЙ ИСКУССТВА НА ОСНОВЕ МЕТАМОДЕРНИСТСКОГО ПОНЯТИЯ «ОСЦИЛЛЯЦИЯ»
}

\section{DEVELOPMENT OF A CONCEPTUAL APPROACH TO THE CREATION OF WORKS OF ART BASED ON THE METAMODERN CONCEPT OF "OSCILLATION»}

\section{Ye. Vasileva}

Summary: The article presents the main concepts of the metamodern philosophy, which formed the basis of the author's artistic project. The article considers the method of creating a work of art based on the reinterpretation of the metamodern philosophy and the transfer of the oscillation principle into artistic practice.

Keywords: metamodernism, philosophy, modern art, method, oscillation.
Васильева Евгения Николаевна

Аспирант, Московский государственный университет имени М.В. Ломоносова deminmikhail@live.com

Аннотация: В статье представлены основные положения философии метамодерна, которые легли в основу художественного проекта автора статьи. Статья рассматривает метод создания художественного произведения, основанного на переосмыслении философии метамодерна и переноса принципа осцилляции на художественную практику.

Ключевые слова: метамодернизм, философия, свременное искусство, метод, осцилляция.

искусством и не искусством и не устанавливает критерии для эстетической оценки произведения искусства [3, с. 42].

Невозможность существования концептуализма, как визуально-обособленного течения, доказывается через силлогизм: 1) Все искусство в той или иной степени концептуально. 2) Ни одно искусство не может быть полностью концептуальным. Из чего следует, что 3) не может быть отдельного вида, называемого концептуальным искусством, в то время как одно искусство может быть более концептуально, чем другое [4, с. 3].

Первый тезис говорит о том, что любое искусство подразумевает процесс создания концепта (замысла), наделенного композицией, формой, посылом и так далее.

Второй тезис, согласно которому любое искусство не может быть полностью концептуальным, объясняется тем, что ни одно произведение не может быть чистым концептом, обобщенной идеей. Любое искусство обретает форму только в каком-либо воплощении - будь то краски, глина, музыка, слова, письмо или движение. Художественное выражение, облеченное в конкретную форму, является одной из определяющих особенностей произведения искусства. Иными словами, искусство подразумевает создание объекта - пусть и не обязательно физического. Если идея существует лишь в форме концепта, то ее следует относить к сфере философии, а не искусства [4, с. 4]. 
Таким образом, концептуальный подход к искусству характеризуется вовсе не наличием замысла (так как замысел существует в любом искусстве), но особым отношением к воплощению. Искусство концепта призвано создавать и развивать нетрадиционные и нетривиальные идеи и практики (в том числе лингвистического характера), а также эксперименты по соединению различных практик в одном произведении.

Все эти особенности концептуального искусства нашли свое отражение в произведении автора проекта, для которого ведущую роль играла идея, нашедшая свое отражение в формировании принципа создания произведения искусства. Основой для проекта послужила философия метамодерна. Причина обращения к этой философской парадигме, которая находится в процессе формирования и не имеет четко определенных границ, состоит в желании выявить новый подход к созданию произведений искусства, который отразил бы современные течения в обществе и философии.

\section{Основы философии метамодерна и понятия "осшимиячия"}

Термин метамодернизм был введен голландскими философами Тимотеусом Вермюленом и Робином ван ден Аккером в 2010 году [5, с. 238]. Метамодернизм переосмысливает основы классического романтизма и возрождает интерес к поиску универсальной истины [6, с. 1]. Таким образом, метамодернизм утверждает, что мироощущение современного человека находится в состоянии колебания между культурами модернизма и постмодернизма [7, с. 92]. Метамодернизм - это сочетание просвещенной наивности, прагматического идеализма, умеренного фанатизма и колебаний между иронией и искренностью, конструкцией и деконструкцией, апатией и влечением ради достижения состояния превосходства (трансцендентности). Поколение метамодернизма осознает, что можно быть ироничными и искренними одновременно - при этом одно необязательно должно вытеснять другое [8, с. 327].

Использование приставки «мета» происходит из платоновского термина metaxis, описывающего колебание между двумя абсолютно противоположными понятиями. Согласно идеям Вермюлена и ван дер Аккера, колебания метамодернизма не должны рассматриваться как некий баланс. «Скорее, это маятник, раскачивающийся между множествами полюсов. Каждый раз, когда энтузиазм метамодернизма качается в сторону фанатизма, серьезность направляет его обратно к иронии. В тот же момент ирония колеблется в сторону апатии, и тогда серьезность (равновесная сила) движет ее обратно в сторону энтузиазма» [9].

Сегодня, когда постмодернистское мышление сменя- ется на новую парадигму под названием метамодернизм, наблюдается импульс к возрождению трансцендентного и архетипического [10, с. 24]. Миф и великие нарративы получают вторую жизнь, интерес к «вечному» и «универсальному» снова становятся актуальным.

Для описания современного социума философия метамодерна выработала ряд терминов. Осцилляция - это колебание между максимами [11, с. 202]. По выражению создателя концепции метамодерна Робина ван ден Акера, «осцилляцию общества и личности можно сравнить с колебанием маятника, который, достигнув одного края, устремляется в противоположный, обеспечивая тем самым непрерывное движение и обновление» [12].

Поэтому метамодернизм объединяет иронию и прагматизм постмодерна, искренность романтизма, рациональность и иррациональность. Несмотря на парадоксальность совмещения противоположных понятий или явлений, осцилляция становится источником движения вперед и достижения нового уровня восприятия реальности.

Само понятие «осцилляция» (колебание) заимствовано из научной терминологии. У растений осцилляция проявляется в виде циркадного ритма (колебания концентрации молекул, связанные со сменой дня и ночи), который позволяет растительному организму балансировать между светлым и темным временем суток [13, с. 3]. Скрытый молекулярный механизм, работающий сиюминутно и реагирующий на все происходящее вовне, помогает растению развиваться и двигаться вперед на протяжении многих лет. Схожие процессы осцилляции наблюдаются и в человеческом мире (чередование экономических кризисов, войн, волн миграций и изменения экологии) [14, с. 24].

В основу художественного метода, разработанного в данной статье, был взят изложенный принцип осцилляции. Однако такие ключевые характеристики метамодерна как возвращение к универсальным идеям модернизма и классическому искусству также нашли отражение в разработанном автором подходе.

\section{Разработка подхода к созданию нового произвеАения искусства}

В рамках работы над проектом был разработан подход к созданию произведений искусства, который можно свести к следующему алгоритму:

1. Анализ философского концепта «осцилляция» и его схематизация;

2. Выбор темы будущей работы и подбор готовой художественной работы автора с целью её дальнейшего развития;

3. «Осцилляционный» анализ работ мастеров, вдох- 
новивших автора, при работе над выбранным произведением;

4. Поиск нового источника вдохновения, в работах которого можно найти новые осциллирующие элементы, не заложенные в предыдущей авторской работе;

5. Выбор материалов для символического выражения отобранных осциллирующих элементов;

6. Создание финальной работы, включающей как старые, так и новые противоположности.

\section{Этап 1}

Первым шагом в создании произведения искусства стала схематизация философского принципа осцилляции (рис. 1). Как было сказано ранее, осцилляция становится источником движения вперед и достижения нового уровня восприятия реальности через парадоксальность совмещения противоположных понятий.

Поэтому новое произведение или новая ступень развития достигается путем анализа противоположностей на существующем этапе (уже созданном произведении) и добавления новых противоположностей, не существовавших ранее. Иными словами, создание произведения искусства построено на дополнении существующего набора характеристик новой парой осциллирующих понятий, которые модифицируют изначальное произведение и вносят новый смысл.

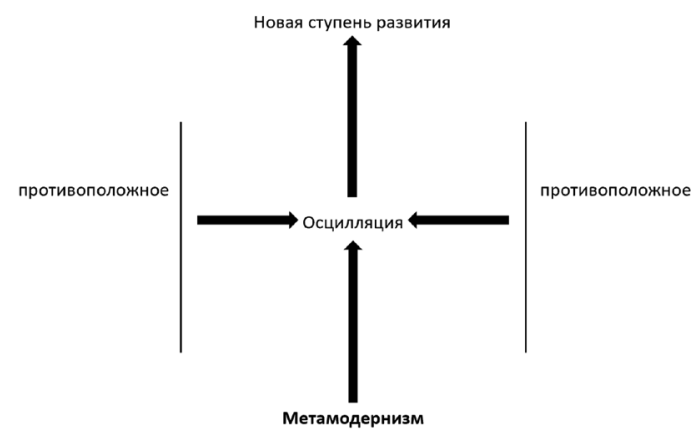

Рис. 1. Схематичное представление принципа осцилляции в философии метамодерна

\section{Этап 2}

Для создания нового произведения автор выбрал тему «По ту сторону». В качестве отправной точки было взято уже имеющееся собственное произведение из проекта «To the wonder» (рис. 2). Данное произведение, построенное на визуальном совмещении противоположностей - черного и белого цветов. Используется цветовая символика, в которой белый выступает символом доброго и невинного, в то время как черный цвет выражает чувство бесперспективности и зла. Человеческие фигуры находятся на грани двух противоположностей, осциллируя между добром и злом в поисках правды.

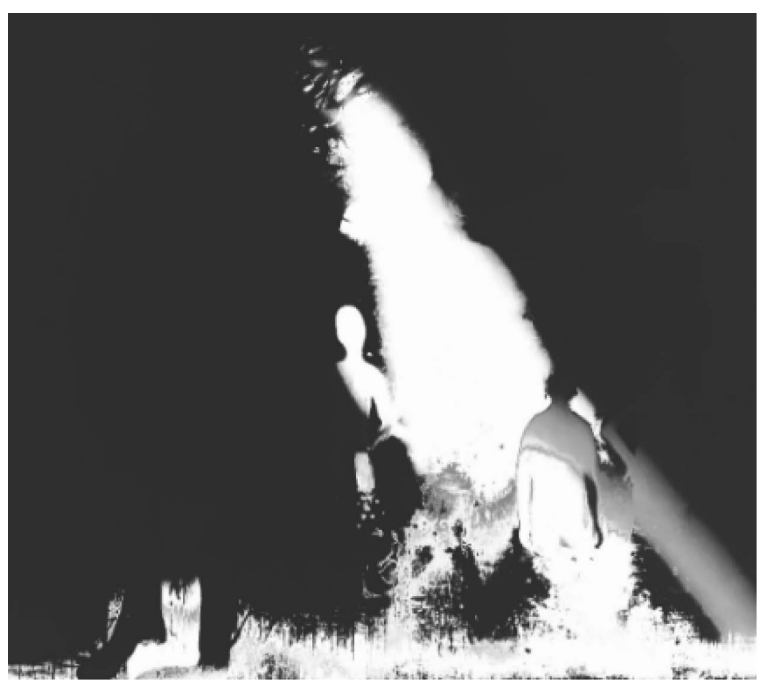

Pис. 2. Eva. To the wonder (2017)

Поиск осциллирующих друг с другом противоположностей в произведениях искусства можно назвать «осцилляционным анализом». В рамках данного проекта сначала были проанализированы картины мастеров прошлого, которые вдохновляли на создание выбранной работы из проекта «То the wonder».

Данный анализ позволил выделить следующие противоположности, заключенные в работах мастеров:

1. Бог - Человек (Микеланджело. Сотворение Адамa);

2. Свет - Тьма (Ансельм Кифер. Человек в лесу);

3. Духовное - Материальное (Вильям Блейк. Великий архитектор);

4. Фантазия - Реальность (Сальвадор Дали. Падший ангел);

5. Смерть - Жизнь (Луи Буржуа. Клетка);

6. Рай - Земля (Ансельм Кифер. Зимний пейзаж);

7. Наслаждение - Боль (Лучио Фонтана. Concetto spaziale).

Все найденные в работах мастеров противоположности можно найти в работе "То the wonder", так как данная работа во многом вдохновлялась темами, идеями и парадоксами рассмотренных картин. Все перечисленные противоположности должны стать основой для нового произведения.

\section{Этап 3}

Для создания нового произведения необходимо было найти новую осциллирующую пару, чтобы внести новый смысл, не имевший место ранее, что схематически представлено на рисунке 3. Новые осцилляци- 
онные пары следует искать в искусстве художников, представляющих интерес для автора, но чей подход отличается от того, что вдохновляло на создание предыдущей работы.

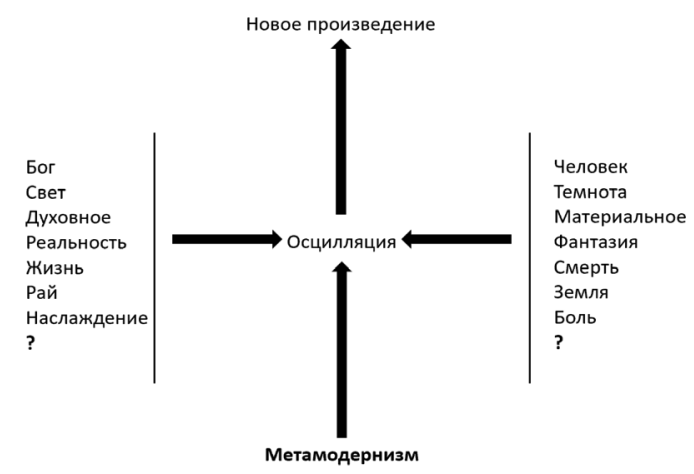

Рис. 3. «Осцилляционный» анализ работы To the wonder

В рамках данного проекта таким художником стал Марсель Дюшан и его работа «Фонтан». Интерес к творчеству Дюшана вызван его связью с концептуальным искусством. Своими корнями концептуальное искусство уходит к движению дадаистов, и, в частности, к работам Марселя Дюшана. Концептуализм вдохновляется такими характеристиками философии Дюшана как антиискусство, антиумение, антиобъект. Дюшан был первый, чей интерес в искусстве смещается в сторону создания теоретических проблем и путей их решения в той форме, которая предпочтительна ему самому (язык, перфоманс, документация, манипуляция окружением). Кроме этого, Дюшан ввел в искусство такое понятие как редимейд, первым переместив объект из нехудожественного пространства в художественное [15, с. 7].

Концептуальный подход, придуманный автором, был использован для анализа произведения «Фонтан». При проведении «осцилляционного» анализа в работе автору удалось найти новую дихотомию противоположностей - Тривиальное и Поэтическое.

\section{Этап 4}

Следующим шагом становится создание произведения искусства на основе найденных осциллирующих понятий. Принципиальной особенностью становится включение всех противоположностей в символической форме в финальное произведение.

В качестве объектов для создания финальной работы выбраны коробка-футляр для ювелирных изделий и швейные иглы. Данные объекты были выбраны через ассоциацию, так как с позиции автора каждый из них содержит в себе и отражает отобранные понятия, визуализируя таким образом осцилляцию между противоположностями (рис. 4).

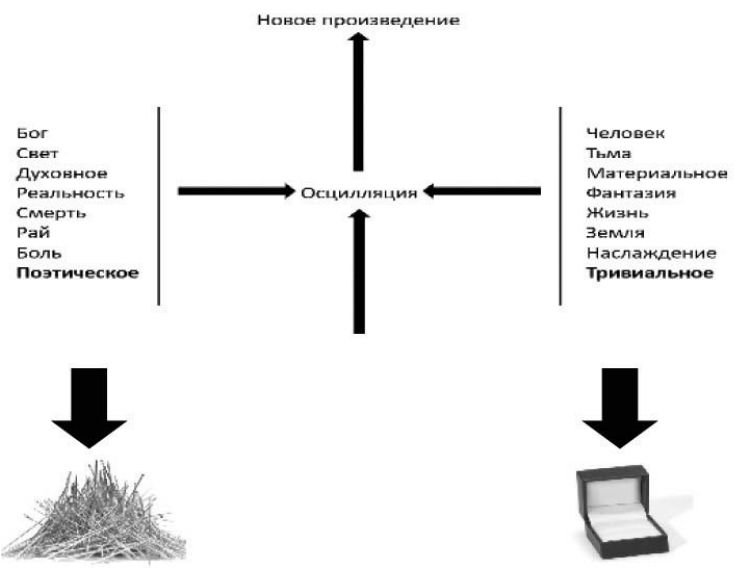

Рис. 4. Список осциллирующих понятий, которые должны быть включены в финальную работу

В рамках данной работы автор ассоциирует Божественное со светом истины, который познается через духовность. Обладая духовностью человек, открывает для себя новое знание, скрытое от материального мира, но путь к духовности связан с болью и страданием. Согласно Библии, Божественный мир был утерян человечеством, изгнанным из Рая, после чего люди стали смертными. Чтобы избавить людей от первородного греха и позволить им снова войти в Рай, Иисус Христос совершил жертву, пройдя через распятие и воскреснув. Образ иглы, с позиции автора, отсылает к символам жертвы Христа.

Работа рассматривает и другую, материальную, сторону человеческого бытия. Человек подвержен соблазнам и стремиться к удовлетворению своих земных, тривиальных потребностей, которые сводятся к погоне за богатством и статусом. Однако такие потребности можно уподобить миражу или фантазии, так как они не могут быть удовлетворены и не дают истинного счастья. Двигаясь по пути земных наслаждений, человек, согласно библейскому учению, движется от божественного света ко тьме. Для изображения данных ассоциаций была выбрана закрытая ювелирная коробка, отражающая идею сокрытой неизвестности, темноты, которая скрывает материальное богатство.

\section{Этап 5}

В результате объединения этих двух материалов был создан малый скульптурный объект, совместивший иглы и футляр таким образом, чтобы отразить осцилляцию между всеми вышеупомянутыми понятиями (Рисунок 5).

Финальная работа построена на парадоксе: приятная внешняя оболочка скрывает разочарование. Предвкушение счастья осциллирует с болью, и в зависимости от того закрыта или открыта коробка, работа передает противоположные чувства, рождает абсолютно различные эмоции. 


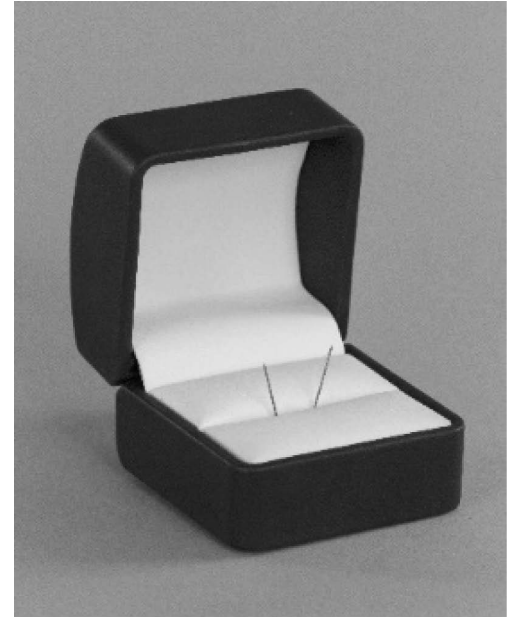

Рис. 5. Финальная работа, полученная в результате применения разработанного метода

Подобно маятнику, о котором говорил Тимотеус Вермюлен, рассуждая о понятии осцилляция, работа переносит из одного спектра чувств в другой, отображая все заложенные в ней противоположности и представляя собой абсолютно новый объект и шаг вперед по сравнению с предыдущим произведением.

\section{Зак^ючение}

Описанный подход представляет собой пример философской мысли в рамках художественной практики и подтверждает тезис о том, что в современном мире художественная деятельность перестает быть обособленной, отдельной от науки сферой. Процесс создания художественного произведения, описанный выше, показывает, что современное искусство может вступать в синтез с философией. Такой синтез не заменяет философское рассуждение, но дополняет его, помогая глубже понять заложенный философами смысл. Он также обогащает искусство новым творческим походом, который позволяет художникам создавать новые современные произведения искусства.

\section{ЛИТЕРАТУРА}

1. Пендикова И.Г., Дмитриева Л.М. Концептуальная идея: эволюция от концептуального искусства до коммуникативного проекта социальной рекламы // Омский научный вестник, н. 6 (102), 2011, с. 236-239.

2. Леванова Е.Ф. Современное искусство и его многомерность // Вестник Томского государственного университета. Культурология и искусствоведение, н. 3 (15), 2014, с. 14-19.

3. Шувалова А.С. Дематериализация арт-объекта концептуального искусства в свидетельствах Люси Липпард // Артикульт, н. 2 (10), 2013, с. $40-57$.

4. Leuthold S. Conceptual Art, Conceptualism, and Aesthetic Education // The Journal of Aesthetic Education. no. 1 (33), 1999, pp. 37-47.

5. Морозов А.В. Осторожно, метамодерн: современность как зонтик и маятник // Galactica Media: Journal of Media Studies, т. 1, н. 3, 2019, с. $238-249$.

6. Павлов А. Образы современности в XXI веке: метамодернизм // Философско-литературный журнал «Логос», т. 28, н. 6 (127), 2018 , с. 1-19.

7. Маркова А.С., Мамукина Г.И. Метамодернизм: преодоление дискретности и индивидуализма // Вестник Московского государственного областного университета. Серия: Русская филология, н. 1, 2019, с. 89-98.

8. Гребенюк А.А. Культурно-исторический анализ переживаний человека эпохи метамодернизма // Азимут научных исследований: педагогика и психология, т. 8, н. 1 (26), 2019, с. 326-330.

9. Вермюлен Т., ван ден Аккер Р. Заметки о метамодернизме [электронный ресурс] URL: http://metamodernism.ru/notes/ (13.04.2019)

10. Сербинская В.А. Постмодернизм и метамодернизм: разграничение понятий и черты метамодернизма в современной литературе // Парадигма: философско-культурологический альманах, н. 26, 2017, с. 22-30.

11. Спиваковский П.Е. Метамодернизм: контуры глубины // Вестник Московского университета. Серия 9. Филология, н. 4, 2018, с. 196-211.

12. Аккер Р. ван ден. Интервью. 2017. 1 марта. URL: http://metamodernizm.ru/robin-van-den-akker/ (accessed: 10.01.2020).

13. Яшин С.А., Самарцев И.Т. Вопросы математического моделирования процессов функционирования органов и систем человека // Концепт, н. 12 (16), 2012, с. 133-138.

14. Коптелов И.О. Экономический цикл и сущность его проявления // Вестник Челябинского государственного университета, н. 10 (264), 2012, с. $24-28$.

15. Осминкин Р.С. От артефакта к арте-акту: реди-мейд как агент социального действия // Артикульт, н. 4 (20), 2015, с. 6-11. 